\title{
Inclusion Complex Formation of Cyclodextrin with Large Dye Molecule
}

\author{
Hidefumi HiraI, Naoki Toshima, and Satoshi Uenoyama \\ Department of Industrial Chemistry, Faculty of Engineering, \\ The University of Tokyo, Hongo, Bunkyo-ku, Tokyo 113, Japan.
}

(Received September 17, 1980)

\begin{abstract}
KEY WORDS Cyclodextrin / $\gamma$-Cyclodextrin / Inclusion / Dye / Methylene Blue / Crystal Violet / Congo Red / Methyl Orange / Induced Circular Dichroism / Dissociation Constant /
\end{abstract}

Cyclodextrins, oligomers of glucose, are known to form inclusion complexes with a variety of molecules or ions, and have been rigorously investigated as a potential model for enzyme ${ }^{1}$ and also for their pharmaceutical application., ${ }^{2,3}$ Most of the reports deal with $\alpha$ - and $\beta$-cyclodextrins. A few water-insoluble complexes of $\gamma$-cyclodextrin have been investigated, ${ }^{4}$ and some of these have been characterized in the chemical structure by the X-ray diffraction method. ${ }^{5}$ However, the water-soluble complexes of $\gamma$-cyclodextrin have hardly been investigated. ${ }^{6}$ The cavity diameters of $\alpha-, \beta$ - and $\gamma$ cyclodextrin are shown to be $5-6,7-8$, and $9-$ $10 \AA$, respectively. ${ }^{3}$ From a comparison of the cavity size, $\gamma$-cyclodetrin can be expected to form an inclusion complex with a large molecule too bulky to be included by $\alpha$ - or $\beta$-cyclodextrin. However, the question is whether $\gamma$-cyclodextrin has an inclusion affinity for larger molecules as high as $\alpha$ - or $\beta$ cyclodextrin does for smaller molecules. In the present study, we choose for the guest molecules about twenty water-soluble dyes, whose molecular weights were from 300-900 and determined the extent of the inclusion affinity of $\gamma$-cyclodextrin in comparison with that of $\alpha$ - or $\beta$-cyclodextrin. We found that (1) four dyes, congo red $\left(\mathrm{C}_{32} \mathrm{H}_{22} \mathrm{O}_{6} \mathrm{~S}_{2} \mathrm{Na}_{2}\right)$, crystal violet $\left(\mathrm{C}_{25} \mathrm{H}_{30} \mathrm{~N}_{3} \mathrm{Cl}\right)$, methylene blue $\left(\mathrm{C}_{16} \mathrm{H}_{18} \mathrm{~N}_{3} \mathrm{SCl}\right)$, and methyl orange $\left(\mathrm{C}_{14} \mathrm{H}_{14} \mathrm{O}_{3} \mathrm{~N}_{3} \mathrm{SNa}\right)$, give the corresponding inclusion complexes with $\gamma$-cyclodextrin, although the first three of these four dyes form no complexes with $\alpha$-cyclodextrin and that (2) the last three of these dyes form $2: 1$ complexes with $\gamma$-cyclodextrin, although congo red forms the $1: 1$ complex.

A solution of dyes $\left(5.0 \times 10^{-5} \mathrm{M}\right)$ in distilled water in both the presence and absence of cyclodextrins $\left(2.5 \times 10^{-3} \mathrm{M}\right)$ was submitted to a measurement of electronic spectra and circular dichroism. Table I shows the results obtained for the above four dyes. Inclusion is indicated by the induction of circular dichroism in the electronic absorption region of the dyes by the addition of cyclodextrin. Methyl orange is shown to be included in three kinds of cyclodextrin. The other three dyes are not included by $\alpha$-cyclodextrin, but can be included by $\beta$ - and $\gamma$-cyclodextrin. This is probably because their molecular sizes are too large to. allow them to be included in the cavity of $\alpha$-cyclodextrin. Dissociation constants, $K_{\mathrm{d}}$, of a cyclodextrin-dye complex was obtained according to the Hildebrand and Benesi equation from the change in the electronic spectra with the concentration of cyclodextrin $(0.1-6 \mathrm{mM})$. In the case of complex of $\gamma$ cyclodextrin with crystal violet, methylene blue, or methyl orange, the 2:1 complex formation was assumed to take place (vide infra). Therefore, the dissociation constants of these complexes were determined by assuming that two molecules of the dye were directly included by $\gamma$-cyclodextrin and that the dimer of the dye did not exist in the solution.

The electronic spectra of crystal violet did not change with the addition of $\alpha$-cyclodextrin. On addition of $\gamma$-cyclodextrin, the spectra change remarkably as shown in Figure 1. The absorbance of 
H. Hirai, N. Toshima, and S. Uenoyama

Table I. Inclusion of dyes by cyclodextrin ${ }^{\mathrm{a}}$

\begin{tabular}{|c|c|c|c|c|c|c|c|c|c|}
\hline \multirow{2}{*}{ Dye } & \multicolumn{4}{|c|}{$\mathrm{UV}-\mathrm{VIS} \lambda_{\max } / \mathrm{nm}$} & \multicolumn{3}{|c|}{$\theta \times 10^{-3 \mathrm{~b}}$} & \multicolumn{2}{|c|}{$K_{\mathrm{d}} \times 10^{5 \mathrm{c}}$} \\
\hline & non & $\alpha-C y D$ & $\beta$-CyD & $\gamma-\mathrm{CyD}$ & $\alpha-\mathrm{CyD}$ & $\beta$-CyD & $\gamma-\mathrm{CyD}$ & $\beta-\mathrm{CyD}$ & $\gamma-\mathrm{CyD}$ \\
\hline Congo red & 498 & 498 & 504 & $\begin{array}{l}496 \\
530 \mathrm{sh}\end{array}$ & 0.0 & 9.2 & 82 & 60 & 5.7 \\
\hline Crystal violet & $\begin{array}{l}504 \text { sh } \\
580\end{array}$ & $\begin{array}{l}540 \mathrm{sh} \\
580\end{array}$ & $\begin{array}{l}543 \mathrm{sh} \\
585\end{array}$ & $\begin{array}{l}548 \\
590 \mathrm{sh}\end{array}$ & 0.0 & 6.0 & 9.8 & 38 & $0.0046^{\mathrm{d}}$ \\
\hline Methylene blue & $\begin{array}{l}614 \\
664\end{array}$ & $\begin{array}{l}614 \\
664\end{array}$ & $\begin{array}{l}617 \mathrm{sh} \\
667\end{array}$ & $\begin{array}{l}610 \\
664\end{array}$ & 0.0 & 9.0 & 8.3 & 110 & $0.019^{\mathrm{d}}$ \\
\hline Methyl orange & 462 & 454 & 454 & 434 & 14.8 & 10.4 & 14.8 & 26 & $0.0062^{\mathrm{d}}$ \\
\hline
\end{tabular}

a $[$ Cyclodextrin $(\mathrm{CyD})]=2.5 \mathrm{mM},[\mathrm{Dye}]=0.05 \mathrm{mM}$ in $\mathrm{H}_{2} \mathrm{O}$.

b Maximum apparent molar ellipticity $\left(\right.$ degree $\left.\cdot \mathrm{cm}^{2} \cdot \operatorname{decimol}{ }^{-1}\right)$.

c Dissociation constant $\left(\mathrm{mol} \cdot \mathrm{dm}^{-3}\right)$ at $20^{\circ} \mathrm{C}$ obtained by assuming the $1: 1$ complex formation, [CyD] $=0.1 \sim 6 \mathrm{mM}$.

${ }^{d}$ Dissociation constant $\left(\mathrm{mol}^{2} \cdot \mathrm{dm}^{-6}\right)$ at $20^{\circ} \mathrm{C}$ obtained by assuming the $2: 1$ complex formation.

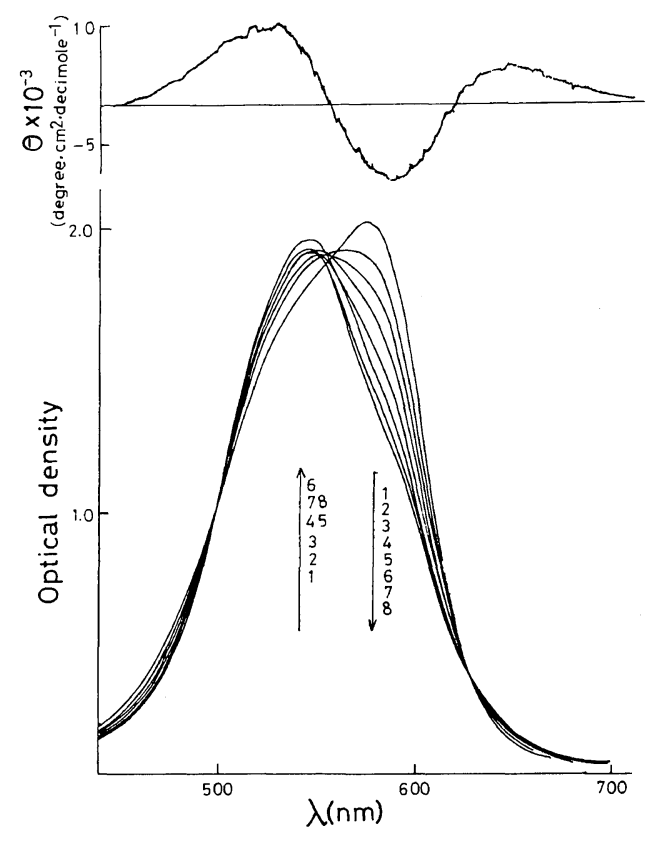

Figure 1. Electronic spectra of crystal violet $(0.05 \mathrm{mM})$ in the absence (1) and presence of $\gamma$-cyclodextrin at concentrations of $0.1(2), 0.2(3), 0.4(4), 0.8$ (5), $1.6(6)$, $3.2(7)$, and $6.4 \mathrm{mM}(8)$ (lower part), and induced circular dichroism of cryatal violet $(0.05 \mathrm{mM})$ in the presence of $\gamma$-cyclodextrin $(2.5 \mathrm{mM})$ (upper part).

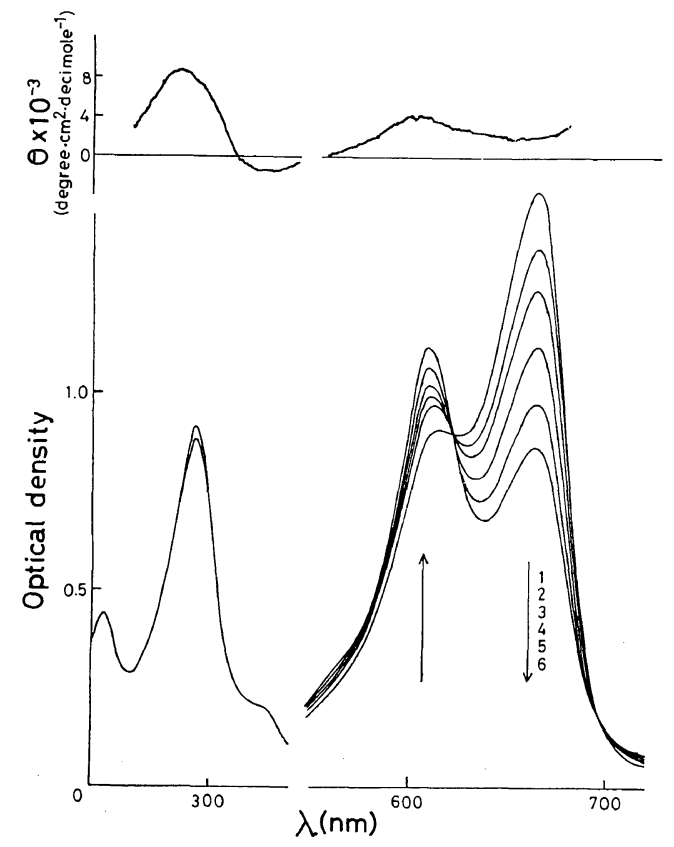

Figure 2. Electronic spectra of methylene blue $(0.025 \mathrm{mM})$ in the absence (1) and presence of $\gamma$-cyclodextrin at concentrations of 0.4 (2), $0.8(3), 1.6(4), 3.2(5)$, and $6.4 \mathrm{mM}$ (6) (lower part), and induced circular dichroism of methylene blue $(0.025 \mathrm{mM})$ in the presence of $\gamma$-cyclodextrin $(2.5 \mathrm{mM})$ (upper part). 


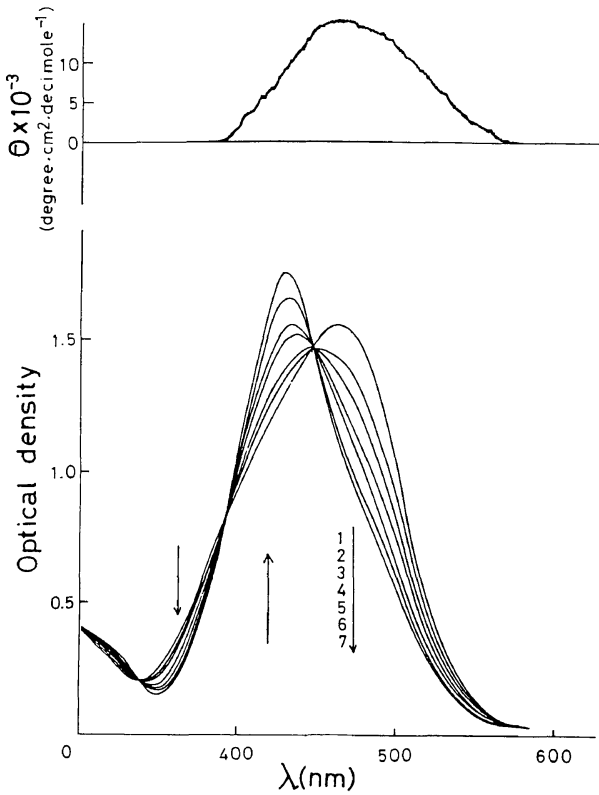

Figure 3. Electronic spectra of methyl orange $(0.05 \mathrm{mM})$ in the absence (1) and presence of $\gamma$-cyclodextrin at concentrations of 0.25 (2), 0.5 (3), 1 (4), 2 (5), 4 (6), and $8 \mathrm{mM}$ (7) (lower part), and induced circular dichroism of methyl orange $(0.05 \mathrm{mM})$ in the presence of $\gamma$-cyclodextrin $(2.5 \mathrm{mM})$ (upper part).

the peak at $580 \mathrm{~nm}$ of crystal violet decreases by addition of $\gamma$-cyclodextrin, and a shoulder peak at $548 \mathrm{~nm}$ increases, and this is attributed to the dimer to crystal violet. ${ }^{7}$ The manner by which a change takes places with increasing concentration of $\gamma$ cyclodextrin is similar to that with increasing concentration of crystal violet itself. This fact suggests that crystal violet dimerizes by the addition of $\gamma$ cyclodextrin even at a low concentration like $0.05 \mathrm{mM}$. In other words, crystal violet is included by $\gamma$-cyclodextrin as a dimer form.

The similar way in which change takes place in the electronic spectra with the addition of $\gamma$-cyclodextrin was observed in the case of methylene blue and methyl orange, but not for congo red, as shown in Figures 2, 3, and 4. On addition of $\beta$-cyclodextrin, the peaks of the electronic spectra shift, and the manner of change is completely different from that observed in the case of $\gamma$-cyclodextrin. In other words, the addition of $\beta$-cyclodextrin rather decreases the shoulder of the electronic spectra attributed to the dimer of the dye. This fact is consistent

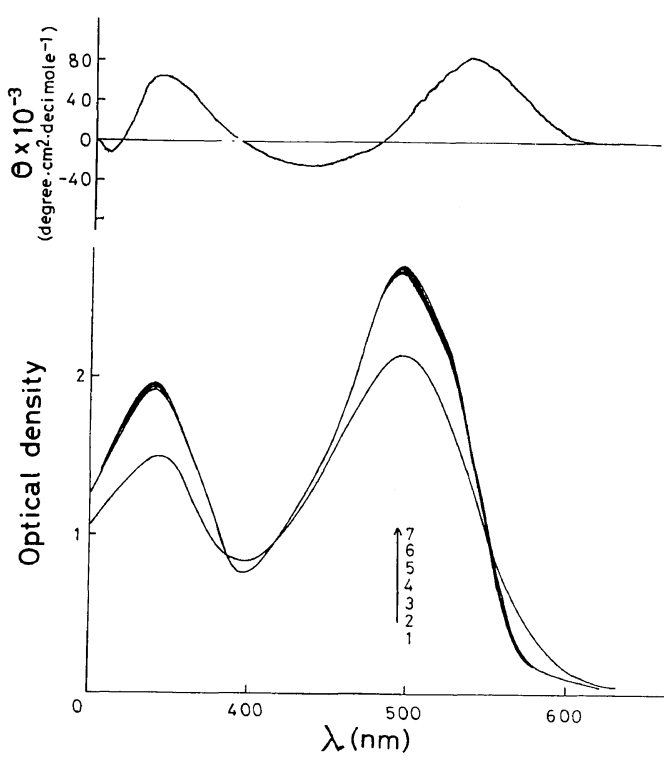

Figure 4. Electronic spectra of congo red $(0.05 \mathrm{mM})$ in the absence (1) and presence of $\gamma$-cyclodextrin at concentrations of 0.25 (2), 0.5 (3), 1 (4), 2 (5), 4 (6), and $8 \mathrm{mM}$ (7) (lower part), and induced circular dichroism of congo red $(0.05 \mathrm{mM})$ in the presence of $\gamma$-cyclodextrin (2.5 mM) (upper part).

with the formation of the $1: 1$ complex of $\beta$-cyclodextrin with the dye.

The 2:1 inclusion complex formation of crystal violet, methylene blue, and methyl orange with $\gamma$ cyclodextrin is supported by the continuous variation method. The apparent ellipticity of induced circular dichroism of the solution at various concentrations of crystal violet and $\gamma$-cyclodextrin was measured with the total concentration kept constant at $6.0 \times 10^{-4} \mathrm{M}$, and is plotted in Figure 5. The maximum induced circular dichroism was observed at the molar ratio of crystal violet and $\gamma$-cyclodextrin being $2: 1$. The same results were obtained by the continuous vaiation for methylene blue and methyl orange. For congo red, however, the results are quite different from those for other three dyes, namely, the peak of the induced circular dichroism appears at the point of the $1: 1$ molar ratio as shown in Figure 6.

The 2:1 complex formation may support the inclusion by $\gamma$-cyclodextrin rather than the simple interaction with it.

In conclusion, crystal violet, methylene blue, and 


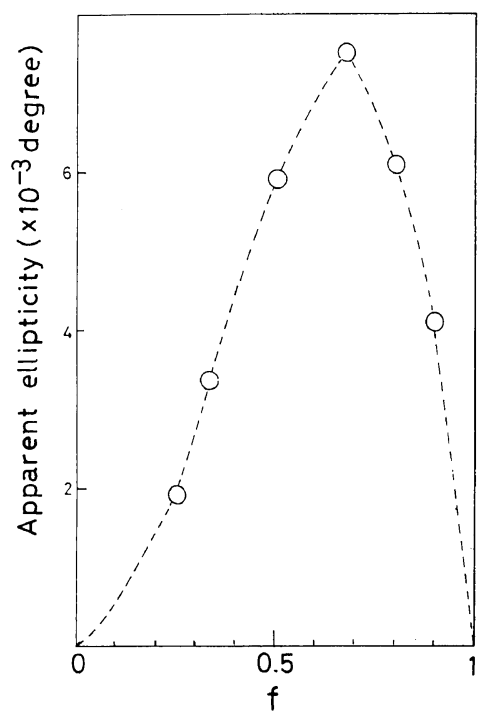

Figure 5. Continuous variation plots of apparent ellipticity at $530 \mathrm{~nm}$ for the crystal violet- $\gamma$-cyclodextrin aqueous system: molar fraction of crystal violet $(f)$ at a total concentration of $6.0 \times 10^{-4} \mathrm{M}$, at $20^{\circ} \mathrm{C}$, using a cell of $0.1 \mathrm{~cm}$ path length, with a precision of $0.4 \times 10^{-3}$ degree.

methyl orange, respectively, form $2: 1$ complexes with $\gamma$-cyclodextrin and congo red forms the $1: 1$ complex. This difference may be due to the dimer formation property of the dye in water and to the fitness of the size of the dimer to the cavity of the $\gamma$ cyclodextrin.

Acknowledgement. The present work was supported in part by a Grant-in-Aid for Scientific Research from the Ministry of Education, Science and Culture of Japan (to H. H.) and by the Takeda Science Foundation (to N. T.).

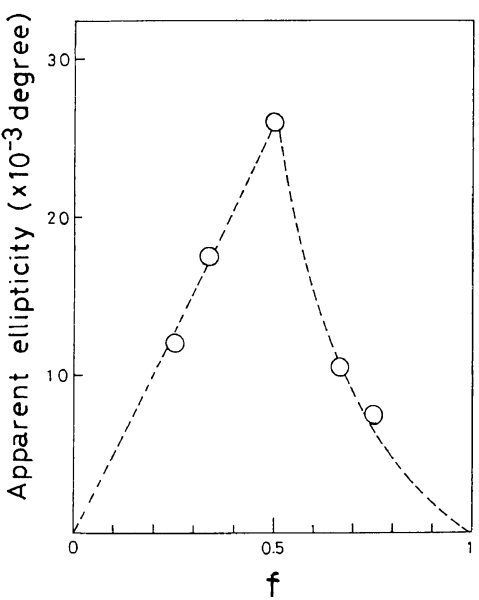

Figure 6. Continuous variation plots of apparent ellipticity at $533 \mathrm{~nm}$ for the congo red- $\gamma$-cyclodextrin aqueous system: molar fraction of congo red $(f)$ at a total concentration of $6.0 \times 10^{-4} \mathrm{M}$, at $20^{\circ} \mathrm{C}$, using a cell of $0.1 \mathrm{~cm}$ path length, with a precision of $0.4 \times 10^{-3}$ degree.

\section{REFERENCES}

1. M, L. Bender and M. Komiyama, "Cyclodextrin Chemistry," Springer-Verlag, Berlin, Heidelberg, and New York, 1978, p 96; W. Saenger, Angew. Chem. Int. Ed. Engl., 19, 344 (1980).

2. K. Uekama, F. Hirayama, M. Otagiri, and K. Ikeda, Chem. Pharm. Bull., 26, 1162 (1978) and references cited therein.

3. A. Mifune and A. Shima, Yuki Gosei Kagaku Kyokai Shi (J. Syn. Org. Chem. Jpn.), 35, 116 (1977).

4. F. Cramer and F. M. Henglein, Chem. Ber., 90, 256 (1957).

5. K. Takeo and T. Kuge, Agr. Biol. Chem., 34, 568 (1970).

6. K. Sensse and F. Cramer, Chem. Ber., 102, 509 (1969); K. Takeo and T. Kuge, Stärke, 24, 281 (1972).

7. W. H. J. Stork, G. J. M. Lippits, and M. Mandel, J. Phys. Chem., 76, 1772 (1972). 